\title{
CONVERTING ENERGY FROM OCEAN CURRENTS
}

\author{
Andrea Fischer ${ }^{1}$, Luiz Emílio B. de Almeida ${ }^{2}$, Alexandre Beluco ${ }^{3}$ \\ ${ }^{I}$ Dr Water Resources, Inst Fed Sul Riograndense, Pelotas, RS, Brazil \\ ${ }^{2}$ Dr Renewable Energy, Inst Pesquisas Hidráulicas, Univ Fed Rio Grande do Sul, Porto Alegre, RS, Brazil \\ ${ }^{3}$ Dr Water Resources, Inst Pesquisas Hidráulicas, Univ Fed Rio Grande do Sul, Porto Alegre, RS, Brazil
}

\begin{abstract}
Ocean energy can be harnessed in different ways. One of those ways is the kinetic energy in water flows. This form of energy is present in ocean currents and tidal streams created when water is forced to flow between coastal barriers. This form of energy corresponds to a significant portion of total energy present in the oceans and very interesting features it presents better predictability and less variability over time, compared with other forms of energy. This article reviews the main settings available to convert energy from currents and discusses some projects in various stages of development.
\end{abstract}

Keywords: Ocean Energy; Sea Currents; Tides; Energy Conversion; Equipments; State of the Art.

\section{INTRODUCTION}

The ocean as an energy resource can be exploited for power generation in one of the following forms: ocean waves, tides, ocean currents, thermal gradients and salinity gradients. The tidal power can be harnessed in two ways, depending on gaps generated by vertical movement of water due to tides or depending on water flows generated by successive filling and emptying of coastal topographic obstacles.

Among these forms of energy, in two of them there is the possibility of generating electricity from the kinetic energy of the flow: the energy of sea currents and tidal energy, as obtained from flows caused by the movement of water masses. Both have great predictability, especially when compared with other renewable resources such as wind power. The flow velocities of ocean currents are lower than the speeds observed in flows due to tides.

The ocean currents are important for maintaining the balance of the planet, and acting on various aspects like the distribution of heat received at low latitudes to higher latitudes; the distribution of salinity, temperature and density; the renewal of marine waters; regional climatic distribution, contributing to the oxygenation of the oceans; the distribution of food, eggs and larvae, to the migration of marine organisms; In addition to a key role in navigation.

In general, the ocean currents are produced mainly by the action of winds, especially seasonal, constant and long period winds, as the trade winds and monsoons, and the difference in physical and chemical characteristics of the water, mainly by the temperature difference and salinity, and also the effect of the earth's rotation and the ocean tides. The currents due to tides are produced by the movement of water associated with the movement of the Earth, Sun and Moon. Such movement occurs on a planetary scale and assumes higher intensities at certain sites throughout the planet. The chains will emerge when this movement of water masses to force the passage of water through obstacles along the coastal topography.
The energy available from the oceans, in the various forms listed above, it is considered important and can have significant potential for supplying energy supply for long term. Ocean energy is also considered as an important alternative for reducing effects associated with climate change. [1] It is clear that these alternatives are conditioned to the economic and technical evolution of devices for energy conversion.

The energy available in currents along the various oceans of the planet exceeds by several times the energy available in other renewable resources. As an example, one thousandth of the available energy in the Gulf Stream is equal to 21,000 times the energy available in Niagara Falls on a stream of water which is equal to 50 times the flow of the rivers of fresh water around the world. [2]

Some factors make the energy of ocean currents a very attractive renewable resource. Among them, a good predictability of available resources, eg better than wind energy; the large concentration of resources available in nature, allowing its use in reasonable quantities with relatively small environmental impacts [3]; the small variability of the available resources, enabling the supply of firm power to interconnected systems.

The energy of ocean currents is considered a renewable resource with reasonable potential for energy supply at reasonable concentrations and large amounts for many decades [4], with the potential to adapt to modern ways of designing a sustainable economy [5].

A growing number of countries are becoming interested in mapping its energy resources, with special attention to resources from the ocean and in particular the energy currents. Countries considered to be developing, such as China [6], Turkey [7], Korea [8], Malaysia [9], India [10] [10] and others [11] have undertaken major efforts in this direction several years ago. 
United Kingdom, the United States, the Netherlands and Norway are developing technology and research in this area. Other countries such as France, Germany, Australia, Canada, New Zealand, Sweden, Spain and Italy, among others, also have ongoing projects. Reference [12] presents a long list of research institutions and companies involved with projects for power generation from currents.

Greater integration of energy from ocean currents in the national energy mix over the world depends on the progress of specific technologies. Obviously, greater integration also depends on social and economic changes that ensure longterm sustainability and sustainability not only from the viewpoint of energy. [13]

Devices for converting energy from sea currents have often been associated with wind turbines for power generation at sea. [14] The characteristics of usual variability of ocean currents, with seasonal and annual periods, allow their inclusion in studies of complementarity with other renewable energy resources. [15]-[16]-[17]

The installation of machines for converting energy from currents in a particular location will hardly be restricted to only one machine. Probably a set of machines will be installed in a particular area. Just like in a wind farm, the positions of these machines must comply with an organization that optimize energy conversion. [18]

The use of ocean current energy in greater quantity by energy systems around the world will increase both with the development of technologies for energy conversion as well as with its use in combination with energy storage devices.

This article focuses on the alternatives currently available for converting energy from ocean currents. The article considers the projects that have already surpassed the initial design stage and the projects that are already in the final stages of development, with testing under real conditions.

\section{ENERGY CONVERSION DEVICES}

The operating principle is based on the conversion of the kinetic energy of water into mechanical energy by the action of moving water on the turbine blades. This mechanical power is then transmitted to the generator, which converts it into electrical power.

The kinetic energy of sea currents can be converted using relatively simple techniques, following similar principles to those used in wind energy, using various types of open rotors [19]. Among the techniques employed, the most common consists of a turbine installed in the flow direction and mounted on a submarine base or suspended on a floating platform.

Among many requirements, the design of a device that will act in ocean waters must consider the rigors of the marine environment, the sealing system of the mechanisms of the equipment corrosion due to saline, the existence of aquatic plants, the possibility of clashes with garbage and objects thrown overboard and care with marine life. Furthermore, because the high density of sea water, the loads experienced by the device can be quite large. Thus, the structure of the equipment must be anchored and designed to withstand the loads without failure. [20]

Repairs and routine maintenance in power systems for marine currents may involve the use of auxiliary vessels, being a disadvantage in relation to wind turbines. For this reason, the design should result in equipment with low maintenance, to reduce the frequency and simplify maintenance procedures. A project where the mechanisms are located above the surface or the prediction of a device to raise the turbine above the surface allows the service on an external platform, substantially simplifying the task.

Previously, the available technology to build equipment was poor, with little durability due to harsh conditions of the marine environment. But advances in engineering, mainly aimed at oil platforms have changed this situation. Most projects have a fairly extensive period of development, approximately 10 years between the conceptual design, modeling and numerical simulation, the study of the characteristics of the planned site for installation, testing prototypes and installation of equipment for operation.

The European Marine Energy Centre [21], EMEC, describes equipment for power generation from waves and from ocean currents. Currently, the EMEC lists over 80 different types of devices [22] for the use of energy from ocean currents. Some of these devices are already installed generating energy, but the majority is in conceptual design phase or prototype testing.

Devices designed to use energy from ocean currents can be classified by their principle of operation: (a) horizontal axis turbines, (b) vertical axis turbines, (c) oscillating hydrofoils, (d) turbines installed inside Venturi duct and (e) other distinct principles.

The method of fixing devices may be classified as: seabed mounted, pile mounted, floating and with hydrofoils inducing down force. The first is fixed to the seabed or is bound by a system of weights. The second type is fixed to one or more columns that are fixed to the ocean floor. This method is similar to the assembly of wind turbine and facilitates maintenance of equipment.

The third type may be rigid, flexible, floating and can have multiple turbines in a same platform and able to move to adapt to variations in level and position. The fourth type, of hydrofoils, there is induction of downward forces which maintains position of the equipment. Hartono [23] suggested a system in which a floating box is attached by cables to a ballast placed on the seabed. This floating box could contain multiple geometries discussed in this article.

The following sections describe some models of horizontal axis turbines, vertical axis turbines, oscillating hydrofoils, enclosed turbines and some other designs. 


\section{MACHINES WITH HORIZONTAL AXIS}

This category includes devices where energy conversion occurs through a component which rotates around a horizontal axis. The most common geometry is the geometry of wind turbines, but there are other possibilities. By building characteristics, the horizontal axis turbines usually require flow velocities above $1 \mathrm{~m} / \mathrm{s}$.

The performance of the horizontal axis turbines is very similar to the wind turbine, but as the water has a density about 830 times greater than the density of the air, the turbine blades can be made smaller and slower rotation. As Horizontal axis turbines typically operate with low speeds, there is less risk for marine animals.

This type of device is the most used and most researched in countries that have coasts with high current speeds, such as some European countries, particularly the UK. The EMEC [22] list around 40 horizontal axis turbines, and some of these turbines are already operating, others are still in prototype testing or in early stages of design.

In the following paragraphs, Evopod, Tidal Stream Turbine, SeaGen, Open Centre Turbine, Swanturbine, Deep Stream Tidal Turbine Gen, Roosevelt Island Tidal Energy, Atlantisstrom, Hales and Hydra Tidal Turbine are described succinctly. These projects do not exhaust the subject and were chosen here only to characterize current trends in design of horizontal axis turbines. Fig. 11 shows schematic representations of these projects.

The Evopod [24] is an English project for flow velocities above $1.0 \mathrm{~m} / \mathrm{s}$. It is fixed with flexible mooring anchored by means of cables, allowing quick installation. By 2008, the turbine was in development on the coast of Northern Ireland, with a prototype in $1 / 10$ scale. More recently, a prototype is being developed in $1 / 4$ scale, with a power of 37 $\mathrm{kW}$, to be integrated into the energy system. The design allows the installation of 39 turbines with $1.5 \mathrm{~m}$ rotor diameter, in an area of approximately one square kilometer, which provide an output valued at approximately $58.5 \mathrm{MW}$. Fig. 1 (a) shows the Evopod showing how it will look installed at sea.

The Tidal Stream Turbine [26]-[27] is a private project developed in Norway for relatively high flow velocities above $2.5 \mathrm{~m} / \mathrm{s}$. The rotor has blades constructed of fiberglass and a prototype with $20 \mathrm{~m}$ rotor diameter can be installed at depths between $40 \mathrm{~m}$ and $100 \mathrm{~m}$. A first prototype capable of generating $0.7 \mathrm{GWh}$ is already in operation and a second prototype will be installed shortly. Project is in the installation of 20 units with commercial production of 32 GWh per year. Fig. 1 (b) shows the turbine.

The SeaGen [29]-[30] is appropriate for speeds above 2.4 $\mathrm{m} / \mathrm{s}$ and the rotor has a diameter ranging between 15 and 20 meters, mounted on steel pile with a diameter of $3 \mathrm{~m}$. A prototype with $300 \mathrm{~kW}$ was installed in 2003 in Lynmouth Devon in the UK, and a commercial turbine was installed in 2008 in Northern Ireland. Fig. 1 (c) shows the SeaGen.

1 The images were used with permission of the companies responsible for the projects ([25]-[28]-[31]-[40]-[42]). (a)

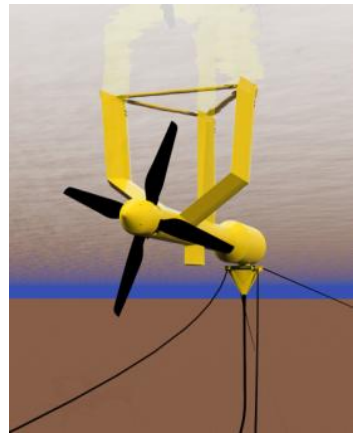

(b)

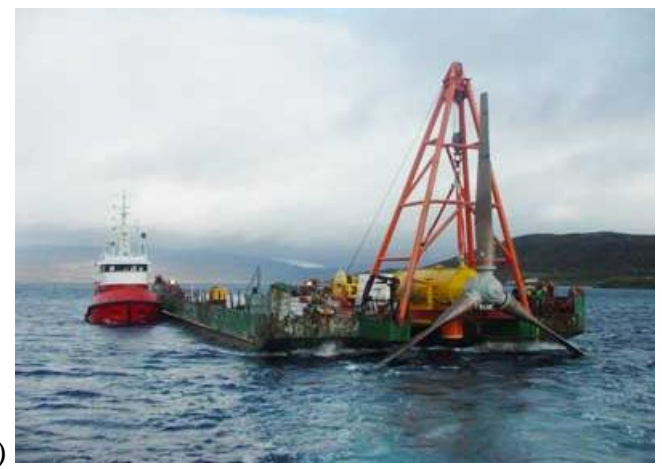

(c)

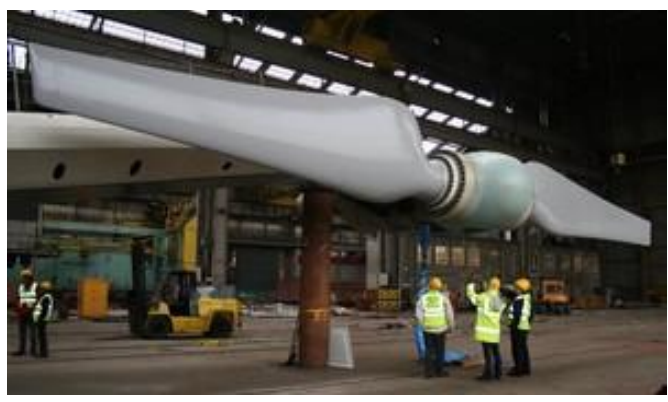

(d)

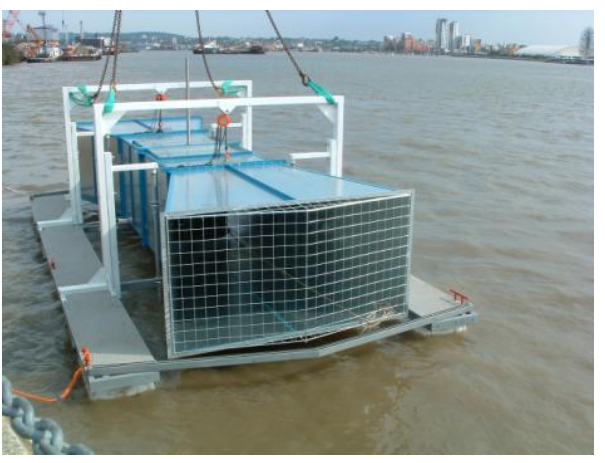

(e)

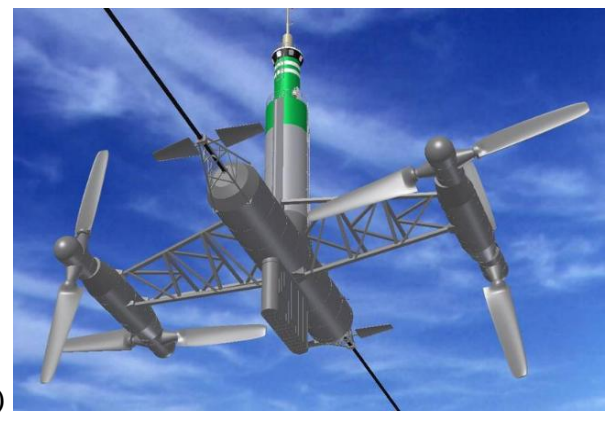

Fig - 1: Machines with horizontal axis: (a) Evopod, (b) Tidal Stream Turbine, (c) Seagen, (d) Hales Turbine and (e) Hydra Tidal. 
The machine developed by Irish company Open Hydro [32] can be manufactured with diameters of $6 \mathrm{~m}$ or $16 \mathrm{~m}$. The installation on the sea bed for turbine with a diameter of $6 \mathrm{~m}$ is designed with two pillars. To turbine with a diameter of $16 \mathrm{~m}$, the structure is performed with three columns and ballast. The depth of the installation site is approximately 35 $\mathrm{m}$. The first turbine was installed for testing in Scotland in Orkney, with the support of the EMEC in 2007. In 2011, began manufacturing the first four turbines with $16 \mathrm{~m}$ diameter, off the coast of France. The expected generation capacity is $2 \mathrm{MW}$.

The Swanturbine [33] is an English project for flow velocities above $1.5 \mathrm{~m} \mathrm{/} \mathrm{s}$ and installation depths of approximately $40 \mathrm{~m}$. The frame is assembled with three ballast and support without the need for drilling the seabed. The machine is in the initial stage of development, with laboratory tests with prototypes in scale $1 / 50$ and $1 / 30$, the University of Wales Swansea and prototyped with $1 \mathrm{~m}$ diameter, properly instrumented to check performance in different conditions speed and flow direction.

The Deep Gen Tidal Stream Turbine [34] is a machine with 140 tons, designed for speeds above $1.0 \mathrm{~m} / \mathrm{s}$. The rotor has a diameter of $18 \mathrm{~m}$ and the turbine can be installed between $30 \mathrm{~m}$ and $80 \mathrm{~m}$ deep. The fixing structure made of steel ballast and three supports, perforating the seabed. Tests were carried out with turbine to generate $500 \mathrm{~kW}$ installed on the island of Orkney, Scotland since 2010. Future project for $1 \mathrm{MW}$ turbine, mounted on the same structure in Orkney. And in (2013/2014) forecast for $10 \mathrm{MW}$ plant on the coast of the UK. The design provides for quick removal and replacement of the nacelle, which can be removed from the support structure by a clamping mechanism, making the maintenance can be performed in a dry environment.

The Roosevelt Island Tidal Energy [35]-[36]-[37], known as RITE, is an American project and is being installed off the city of New York, along the east coast of Roosevelt Island. The rotor has a diameter of $5 \mathrm{~m}$ and is fixed by a pillar. The assembly is modular in order to facilitate assembly and disassembly. From 2002 to 2006 were conducted prototype testing, from 2006 to 2008 experiments were performed with full-scale equipment, and from 2009 to 2012 were held the final stage of the project.

The Atlantisstrom [38] operates with flow rates above 1.0 $\mathrm{m} / \mathrm{s}$. The machine has $20 \mathrm{~m}$ long, with a rotor diameter of 8 $\mathrm{m}$ and constructed with eight blades. It is fixed by drilling two points on the seabed. The project is at the stage of prototype testing at 1/10 scale, built of steel used in the shipping industry and painted with a silicone base.

The Hales turbine [39] has articulated blades so as to offer minimum resistance to the flow and absorb energy. In addition, the blade area produces very high amounts of torque at slow speed. The minimum speed for operation is $1.0 \mathrm{~m} / \mathrm{s}$. The turbine is coupled to the generator, reaching 10 to $16 \mathrm{rpm}$. It is fixed by drilling two points on the seabed. The project is at the stage of prototype testing. Fig. 1 (d) shows the Hales. The company intends to offer to the market a Venturi-ducted version of the Hales turbine.

Hydra Tidal II [41] is a machine with a diameter of $23 \mathrm{~m}$. The turbine blades are made of laminated wood. The device is installed in Lofoten, Norway, since 2010, with a generation capacity of $1.5 \mathrm{MW}$. The method of attachment is a floating structure with four turbines installed with the possibility of anchoring at different depths. Fig. 1 (e) presents the Hydra Tidal.

A proposal that is geometrically similar to the Hydra was presented in References [43] and [44]. It is a group formed by a wing and two turbines attached by cables to the seabed. The wing allows a flight across the stream in search of positions that allow optimized energy generation. Currently is being tested with small-scale prototypes.

\section{MACHINES WITH VERTICAL AXIS}

This category includes devices where energy conversion occurs through a component which rotates around a vertical axis. Most designs of vertical axis turbines have initial inspiration on the vertical axis windmill patented by French inventor, Georges Darrieus, also known as Darrieus turbine, in the 30 s.

The vertical axis turbines have the same working principle of horizontal axis turbines. Points favorable and unfavorable points of the machines with vertical axis are enhanced in the same way by the higher density of the medium. The EMEC [22] list 16 types of vertical axis turbines that are either in the design phase as already in operation.

In the following paragraphs, the designs of Blue Energy, Gorlov, Neptune Proteus, Kobold and Encurrent are described succinctly. These projects do not exhaust the subject and were chosen here only to characterize current trends in design of vertical axis turbines. Fig. 22 shows schematic representations of these projects.

The turbine known as Blue Energy [45]-[46] has been developed by aerospace engineer Barry Davis for two decades in Canada. She has four rotor blades and operates with minimum speed of flow of $1.0 \mathrm{~m} / \mathrm{s}$. The supporting structure is anchored to the seabed in ballast concrete. The coupling, gear box and generator are located above the water surface, facilitating access for maintenance. The rotor is constructed from stainless steel and has a steel shaft with anti-corrosion coating. Currently, tests are being carried out in laboratory prototypes. Fig. 2 (a) shows the Blue Energy.

The Gorlov Turbine [48] was developed by Alexander Gorlov, professor of mechanical engineering at Northeastern University in Boston. The prototype was built with three rotor blades and rotor diameter of approximately $1.0 \mathrm{~m}$. Prototype tests were performed in Vinalhaven, on the coast of Maine and in the Amazon River in Brazil.

2 The images were used with permission of the companies responsible for the projects ([47]-[52]). 


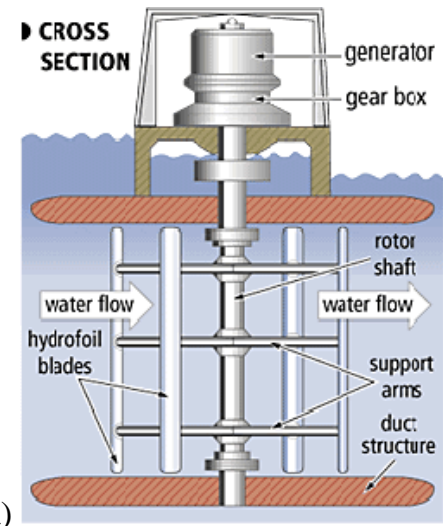

(a)

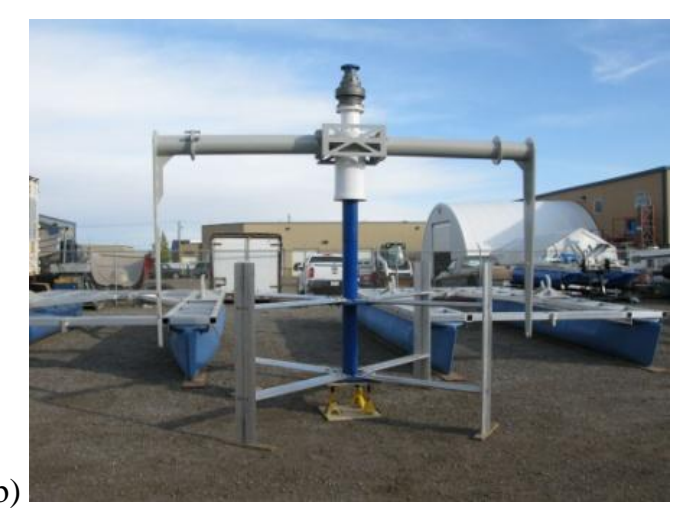

Fig - 2: Machines with vertical axis: (a) Blue Energy and (b) Encurrent.

Neptune Proteus NP 1000[49] is a plan for flow velocity of $2.5 \mathrm{~m} / \mathrm{s}$. A prototype rotor with $6.0 \mathrm{~m}$ diameter and structure with 160 tons has been tested since 2010, after studies with prototypes in scales $1 / 100,1 / 40$ and $1 / 10$. The equipment must be installed on a floating platform anchored, with freedom of movement.

The Kobold [50] is a device being tested in the Strait of Messina, Italy, by the Company Ponte di Archimede International in collaboration with several European partners. The equipment has two rotors with three blades each.

The Encurrent [51] is a device suitable to operate in estuaries, rivers and canals, for minimum flow velocity of $1.5 \mathrm{~m} / \mathrm{s}$. The turbine placed on the floating structure is coupled to a permanent magnet generator located at the surface of the water. The turbines are constructed for different power ratings: $5,10,25,125$ and $250 \mathrm{~kW}$, so there are different rotor diameters. The development phase can be considered overcome and several units are already in operation. Fig. 2 (b) shows the Encurrent.

\section{OSCILATING HYDROFOILS}

This type of device consists of a hydrofoil attached to vibrating rod and the movement is caused by the current in both sides, like in a wing, resulting in upward and downward movements. These movements are alternated and repetitive. This motion is transmitted to a hydraulic system to be converted into electricity.

In the following paragraphs, Pulse Generator, Sea Snail, Stingray Tidal Stream Generator and Biostream are described. These projects do not exhaust the subject and were chosen here only to characterize the current trends of design oscillating hydrofoils. Fig. 33 shows schematic representations of some projects of this section.

The design of the Pulse Generator [53] was made for installation in shallow water, causing the device to capture energy through a hydrofoil that has a scanning area in the form of a rectangle whose length is independent of water depth. In conventional turbines to scan the flow area has the shape of a circle whose diameter should be significantly less than the depth of the water, making it difficult to install in shallow water. Fig. 3 (a) shows the Pulse Generator.

A full-scale device of the Sea Snail [55] has been produced and is operating in Orkney, UK. The structure remains near the seabed by a number of airfoils mounted on a frame for inducing counter forces to the direction of flow. If the flow velocity increases, there comes a moment that forces the opposite hydrofoils down. For this, it is considered that the proportion of surface area is such that the downward force generated exceeds the moment of turning, causing the device to remain in position. This type of mechanism, with hydrofoils reduces impacts on the seabed.

The Stingray Tidal Stream Generator [56] consists of a hydrofoil with angle of attack relative to the direction of the current variable. This causes the support arm to oscillate forcing hydraulic cylinders to a reciprocating motion. The hydraulic oil pressure increases, allowing the operation of a generator.

(a)
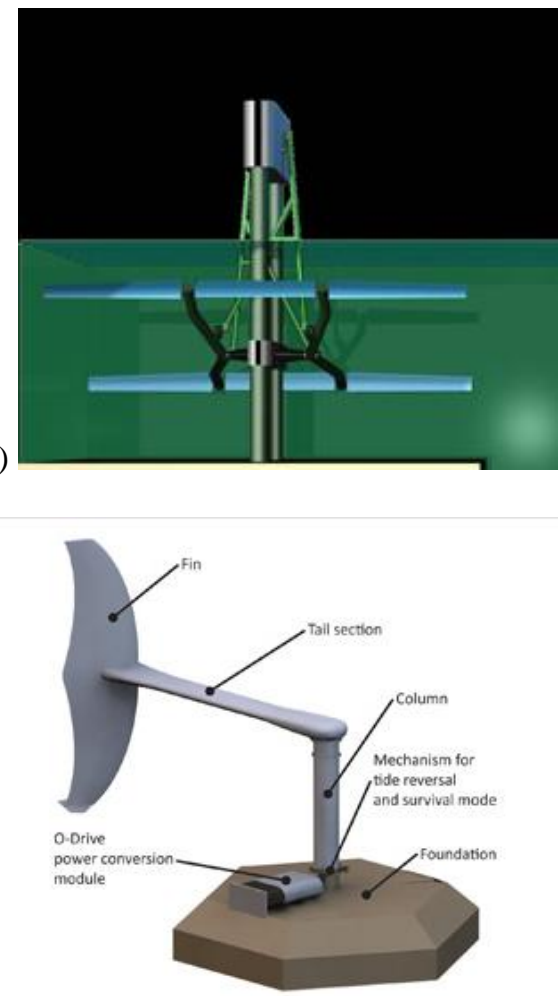

(b)

Fig - 3: Oscillating hidrofoils: (a) Pulse Generator and (b) Biostream.

3 The images were used with permission of the companies responsible for the projects ([54]-[58]). 
The Biostream [57] is an Australian design inspired by shapes and movements of nature. It is a shovel-shaped fin fish which operates as a hydrofoil, inducing oscillatory motion to a swing arm. The minimum rate of flow is high, $2.5 \mathrm{~m} / \mathrm{s}$. The first prototype is under construction and will be installed in Flinders islands, Tasmania. Fig. 3 (b) shows the Biostream.

\section{MACHINES INTO VENTURI TUBES}

The installation of a device inside a Venturi tube creates an effect of concentration of the flow passing through the turbine, increasing the flow velocity. Runoff can directly drive a turbine or may induce a pressure differential to drive a turbine.

The following paragraphs describe Clean Current and Rotech Tidal Turbine. These projects are very similar and do not exhaust the subject, having been chosen here only to characterize current trends in the design of machines placed in Venturi tubes.

Clean Current's equipment [59] operates at speeds of about $3 \mathrm{~m} / \mathrm{s}$, with speeds between 20 and $70 \mathrm{rpm}$, fixed on the seabed. It is a family of turbines for operation from $5 \mathrm{~m}$ to $13 \mathrm{~m}$ depth, with rotor diameter of $3.5 \mathrm{~m}$ to $10 \mathrm{~m}$. The largest equipment generates around $500 \mathrm{~kW}$.

To mitigate problems with animals, the rotation is low and the turbine has a central hole with $1 \mathrm{~m}$ diameter, providing a safe passage through the unit. There flaps on the front and back of the rotor to facilitate the escape of the animals. However, small marine species may be damaged by the passage between rotor blades.

The Rotech Tidal Turbine design [60] is focused on simplicity and robustness. It consists of a bi-directional horizontal axis turbine installed inside a symmetrical Venturi duct. The diameter of the Venturi is $15 \mathrm{~m}$, the diameter of the turbine is $11.5 \mathrm{~m}$ and $19.2 \mathrm{~m}$ length. It can be installed up to $40 \mathrm{~m}$ deep, with mounting via ballast without drilling the seabed. Fig. 44 shows a representation of this project.

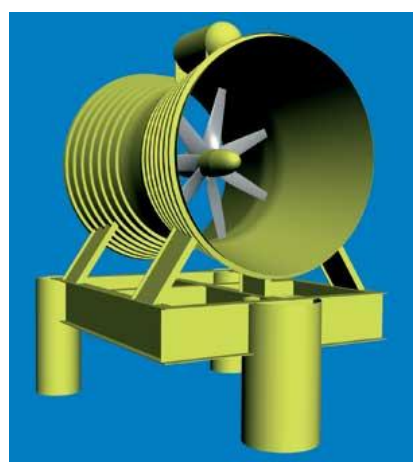

Fig - 4: Machine inserted in Venturi tubes: Rotech Tidal Turbine.

4 The images were used with permission of the companies responsible for the projects ([61]).
These two projects are very similar, suitable for relatively high flow velocities at shallow depths. They are well suited to the design of power generation farms in locations with reasonable potential of ocean currents and tides.

\section{OTHER VIEWS}

This section dealt with projects that do not fit in previous categories. In the following paragraphs, Transverse Horizontal Axis Water Turbine and Blue Tec are described. These projects do not exhaust the subject.

The design of Axis Transverse Horizontal Water Turbine [62], THAWT, consists of a rotor placed transversely to the flow. The rotor design allows 50\% more production than conventional propellers. The prototype has rotor diameter of $10 \mathrm{~m}$ and length $50 \mathrm{~m}$, placed at a depth of $20 \mathrm{~m}$. A machine with two rotors must operate with reasonable efficiency at low speeds, but has the capacity to generate $2.4 \mathrm{MW}$ with a flow rate of $2 \mathrm{~m} / \mathrm{s}$ and $5.3 \mathrm{MW}$ at $2.5 \mathrm{~m} / \mathrm{s}$. Fig. 55 shows schematic representation of this project.

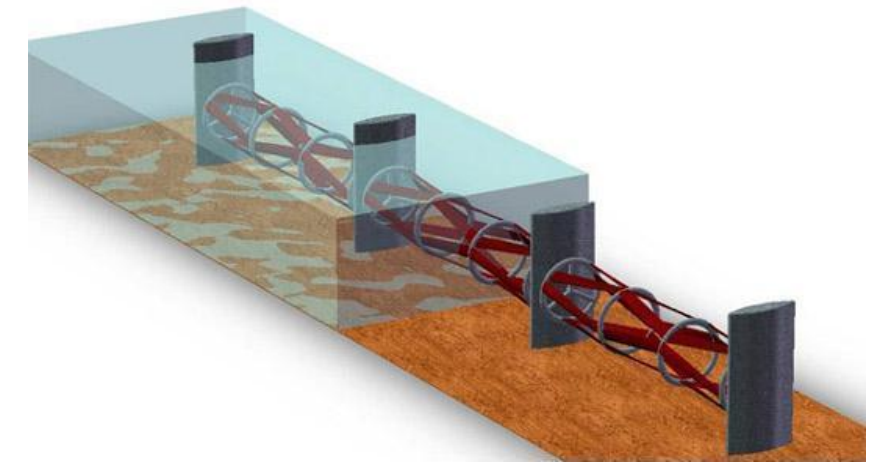

(a)

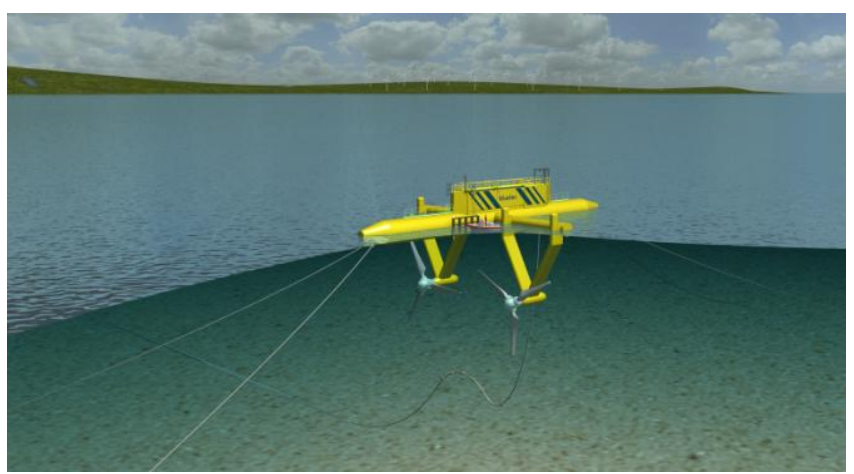

(b)

Fig - 5: THAWT, Transverse Horizontal Axis Water Turbine.

The Blue Tec [64] is still in the conceptual stage of development, consisting primarily of a floating platform for installing generation equipment to be integrated into the energy system. The structure can support two to four turbines of horizontal or vertical axis, with a total generating capacity of some MW. It is a floating platform anchored to the seabed by cables.

5 The images were used with permission of the companies responsible for the projects ([63]). 
As the equipment developed for generation of energy from currents have not yet reached maturity, there is much receptivity to creative and innovative solutions.

Reference [65] presents a proposal for a floating platform and a turbine with inclined axis, with similar configuration settings to vertical axis turbines described above. It is a proposal with advantage regarding operation and maintenance of the machines, having as disadvantage that can extract energy just of flows superficial.

\section{FINAL REMARKS}

This paper presented the configurations of the power conversion devices, as classified by their principle of operation. The technologies for current energy conversion are still in development, and there is none in a state of technical and economic maturity. During this period, therefore, there may be several projects with innovative designs and that might not prove feasible.

The operating conditions for such equipment, immersed in seawater, are quite difficult, but the energy potential is enormous. This development phase of the equipment emphasizes the largest displacement speed of the water, but the next stages should also reveal equipment to convert the energy present also in lower speeds (currently unavailable). The use of ocean current energy in greater quantity by energy systems around the world will increase both with the development of technologies for energy conversion as well as with its use in combination with energy storage devices.

\section{ACKNOWLEDGEMENT}

This work was developed as a part of research activities on renewable energy developed at the Instituto de Pesquisas Hidráulicas, Universidade Federal do Rio Grande do Sul, in southern Brazil. The authors acknowledge the support received from the institution.

\section{REFERENCES}

[1] Lewis, A. Estefen, S. Huckerby, J. Musial, W. Pontes, T. Torres-Martinez, J. (2011) Ocean energy, In: IPCC Special Report on Renewable Energy Sources and Climate Change Mitigation [Edenhofer, O. Pichs-Madruga, R. Sokona, Y. Seyboth, K. Matschoss, P. Kadner, S. Zwickel, T. Eickemeier, P. Hansen, G. Schlömer, S. Von Stechow C. (eds)], Cambridge University Press, Cambridge, United Kingdom and New York, NY, USA.

[2] Moreno, N. Sallent, R. Espi, A. Bao, D. Teillet, Y. (2006) Ocean current energy potential on the U.S. Outer Continental Shelf. U.S. Department of Interior. Available at www.exergy.se/goran/hig/re/08/ocean.pdf. Accessed on April 29, 2013.

[3] Bahaj, A.S. Myers, L.E. (2003) Fundamentals applicable to the utilization of marine current turbines for energy production. Renewable Energy, v.28, p.2205-2211.

[4] Twidell J., Weir T., 2006. Renewable Energy Resources. $2^{\mathrm{a}}$ ed. Taylor \& Francis Group. Londres. 601 p. Disponível em <www.eBookstore.tandf.co.uk>.

[5] Lodhi, M.A.K. (1988) Power potential from ocean currents for hydrogen production. International Journal of
Hydrogen Energy, v.13, p.151-172.

[6] Wang, S. Yuan, P. Li, D. Jiao, Y. (2011) An overview of ocean renewable energy in China. Renewable and Sustainable Energy Reviews, v.15, p.91-111.

[7] Sen, Z. (2012) Energy generation possibility from ocean currents: Bosphorus, Istanbul. Ocean Engineering, v.50, p.31-37.

[8] Kim, G. Lee, M.E. Lee, K.S. Park, J.S. Jeong, W.M. Kang, S.K. Soh, J.G. Kim, H. (2012) An overview of ocean renewable energy resources in Korea. Renewable and Sustainable Energy Reviews, v.16, p.2278-2288.

[9] Chong, H.Y. Lam, W.H. (2013) Ocean renewable energy in Malaysia: the potential of the Straits of Malacca. Renewable and Sustainable Energy Reviews, v.23, p.169178.

[10] Hammar, L. Ehnberg, J. Mavume, A. Cuamba, B.C. Molander, S. (2012) Renewable ocean energy in the Western Indian Ocean. Renewable and Sustainable Energy Reviews, v.16, p.4938-4950.

[11] International Energy Agency, IEA (2003) Implementing Agreement on Ocean Energy Systems, Status and research and development priorities, Wave and marine current energy. Available at www.ocean-energysystems.org/oes_documents/annex_i_reports/. Accessed on May 06, 2013.

[12] Finkl, C.W. Charlier, R. (2009) Electrical power generation from ocean currents in the Straits of Florida: some environmental considerations. Renewable and Sustainable Energy Reviews, v.13, p.2597-2604.

[13] van Vuuren, D.P. Nakicenovic, N. Riahi, K. BrewHammond, A. Kammen, D. Modi, V. Nilsson, M. Smith, K.R. (2012) An energy vision: the transformation towards sustainability - interconnected challenges and solutions. Current Opinion in Environmental Sustainability, v.4, p.1834.

[14] Esteban, M. Leary, D. (2012) Current developments and future prospects of off shore wind and ocean energy. Applied Energy, v.90, p.128-136.

[15] Beluco, A. Souza, P.K. Krenzinger, A. (2008) A dimensionless index evaluating the time complementarity between solar and hydraulic energies. Renewable Energy, v.33, p.2157-2165.

[16] Beluco, A. Souza, P.K. Krenzinger, A. (2012) A method to evaluate the effect of complementarity in time between hydro and solar energy on the performance of hybrid hydro PV generating plants.. Renewable Energy, v.45, p.24-30.

[17] Beluco, A. Souza, P.K. Krenzinger, A. (2013) Influence of different degrees of complementarity between hydro and solar energy on the performance of hybrid hydro PV generating plants. Energy and Power Engineering, v.5, n.3.

[18] Lee, S.H. Lee, S.H. Jang, K. Lee, J. Hur, N. (2010) A numerical study for the optimal arrangement of ocean current turbine generators in the ocean current power parks. Current Applied Physics, v.10, p.S137-S141.

[19] EUREC Agency (1996) The future for renewable energy: prospects and direction. London, UK: Jones \& Jones Ltd.

[20] Ponta, F.L., Jacovkis, P.M. (2007) Marine-current power generation by diffuser-augmented floating hydroturbines. Renewable Energy, v.33, p.665-673.

[21] European Marine Energy Centre, EMEC (2014) Marine energy, www.emec.org.uk/marine-energy/. 
Accessed on September 02, 2014.

[22] European Marine Energy Centre, EMEC (2014)

Tidal energy developers, www.emec.org.uk/marineenergy/tidal- developers/. Accessed on September 02, 2014.

[23] Hartono, W. (2002) A floating tied platform for generating energy from ocean current. Renewable Energy, v.25, p.15-20.

[24] Ocean Flow Energy (2014) Evopod energy conversion device, www.oceanflowenergy.com/. Accessed on September 03, 2014.

[25] Mackie, G. (2014) Personal correspondence.

[26] Andritz Hydro Hammerfest (2013) HS300 Tidal Stream Turbine, www.hammerfeststrom.com/products/tidalturbines/hs300/. Accessed on March 20, 2013.

[27] Andritz Hydro Hammerfest (2013) HS1000 Tidal Stream Turbine, www.hammerfeststrom.com/products/tidalturbines/hs1000/. Accessed on March 20, 2013.

[28] Mathisem, I.L. (2012) Personal correspondence.

[29] Marine Current Turbine (2013) Seagen S system, http://www.marineturbines.com/SeaGen-Products/SeaGen-

S. Accessed on March 20, 2013.

[30] Marine Current Turbine (2013) Seagen U system, http://www.marineturbines.com/SeaGen-Products/SeaGen-

U. Accessed on March 20, 2013.

[31] Scarsbrook, V. (2012) Personal correspondence.

[32] Open Hydro Tidal Technology (2013) Open Centre Technology, www.openhydro.com/techOCT.html. Accessed on March 20, 2013.

[33] Swanturbines (2013) Tidal energy system, www.swanturbines.co.uk/technology-development/.

Accessed on March 20, 2013.

[34] Tidal Generation, an Alstom Company (2013) Deep Gen tidal stream turbine, www.tidalgeneration.co.uk/products/. Accessed on March 20, 2013.

[35] Verdant Power (2013) Free Flow Kinetic Hydropower System, verdantpower.com/what-systemsint/. Accessed on March 20, 2013.

[36] Verdant Power (2013) The RITE project, verdantpower.com/what-initiative/. Accessed on March 20, 2013.

[37] Verdant Power (2013) The CORE project, verdantpower.com/what-core/. Accessed on March 20, 2013.

[38] Atlantisstrom (2013) Atlantisstrom, www.atlantisstrom.de/description.html. Accessed on March 20, 2013.

[39] Hales Water Turbines (2014) Hales turbine, www.hales-turbine.co.uk/how.html. Accessed on September 03, 2014.

[40] Hales, P. (2014) Personal correspondence.

[41] Hydra Tidal (2013) Morild II tidal power plant, www.hydratidal.info/\#!technology. Accessed on March 20, 2013.

[42] Tørud, A. (2012) Personal correspondence.

[43] VanZwieten, J. Driscoll, F.R. Leonessa, A. Deane, G. (2006) Design of a prototype ocean current turbine - part I: mathematical modeling and dynamics simulation. Ocean Engineering, v.33, p.1485-1521.

[44] VanZwieten, J. Driscoll, F.R. Leonessa, A. Deane, G. (2006) Design of a prototype ocean current turbine - part II: flight control system. Ocean Engineering, v.33, p.15221551 .

[45] Blue Energy (2013) Vertical Axis Hydro Turbine, www.bluenergy.com/technology_method_vaht.html. Accessed on March 20, 2013.

[46] Blue Energy (2013) Tidal Bridge, www.bluenergy.com/technology_method_tidal_bridge.html. Accessed on March 20, 2013.

[47] Ellison, J. (2012) Personal correspondence.

[48] Lucid Energy (2013) Lucid Pipe Power System, www.lucidenergy.com/lucid-pipe/. Accessed on March 20, 2013.

[49] Neptune Renewable Energy (2013) Neptune Proteus NP-1000, www.neptunerenewableenergy.com/. Accessed on March 20, 2013.

[50] Ponte di Archimede International. Apresenta o dispositivo denominado "Kobold". Disponível em <www.pontediarchimede.it>. Acesso em novembro/2011.

[51] New Energy Corporation (2014) EnCurrent Power Generation

System, www.newenergycorp.ca/Products/PowerGeneration/tabid/89 /Default.aspx. Accessed on September 03, 2014.

[52] Bear, C. (2014) Personal correspondence.

[53] Pulse Tidal (2013) Pulse Stream 100, pulsetidal.com/our-technology.html. Accessed on March 20, 2013.

[54] Nimmo, H. (2012) Personal correspondence.

[55] Centre for Research in Energy and the Environment, Robert Gordon University (2013) Sea Snail, www4.rgu.ac.uk/cree/general/page.cfm?pge=10769.

Accessed on March 20, 2013.

[56] IHC Merwede (2013) Stingray Tidal Stream Generator, . Accessed on March 20, 2013.

[57] BioPower Systems (2013) BioStream, www.biopowersystems.com/biostream.html. Accessed on March 20, 2013.

[58] Prill, S. (2012) Personal correspondence.

[59] Clean Current, Renewable Energy Systems (2014) Tidal turbines, www.cleancurrent.com/tidal-turbines. Accessed on September 04, 2014.

[60] Lunar Energy (2014) Rotech Tidal Turbine, www.lunarenergy.co.uk/productOverview.htm. Accessed on September 05, 2014.

[61] Tyrrell, A. (2012) Personal correspondence.

[62] Kepler Energy (2014) Transverse Horizontal Axis Water Turbine, www.keplerenergy.co.uk/about-html.php. Accessed on September 03, 2014.

[63] Dixon, P. (2014) Personal correspondence.

[64] Blue Water Energy (2014) BlueTec tidal energy converter, www.bluewater.com/bluetec. Accessed on September 04, 2014.

[65] Akimoto, H. Tanaja, K. Usawa, K. (2013) A conceptual study of floating axis water current turbine for low cost energy capturing from river, tide and ocean currents. Renewable Energy, v.57, p.283-288.

[66] Bahaj, A.S. (2011) Generating electricity from the oceans. Renewable and Sustainable Energy Reviews, v.15, p.3399-3416.

[67] Rourke, F.O. Boyle, F. Reynolds, A. (2010) Marine current energy devices: current status and possible future applications in Ireland. Renewable and Sustainable Energy Reviews, v.14, p.1026-1036. 